\title{
KAJIAN PEMELIHARAAN RUTIN PADA GEDUNG REKTORAT UNIVERSITAS TEUKU UMAR
}

\author{
Edi Mawardi ${ }^{1)}$, Samsunan ${ }^{2)}$, Fathurrahman ${ }^{3)}$ \\ Jurusan Teknik Sipil, Fakultas Teknik \\ Universitas Teuku Umar, Alue Peuyareng Meulaboh 23615

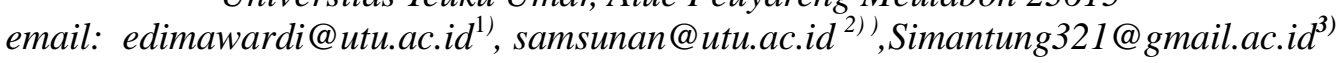

DOI: http://dx.doi.org/10.29103/tj.v10i1.276

(Received: January 2020 / Revised: February 2020 / Accepted: March 2020)

\begin{abstract}
Abstrak
Pemeliharaan bangunan merupakan persyaratan yang harus dilakukan, terutama bangunan untuk kepentingan umum. Gedung Rektorat Universitas Teuku Umar merupakan pusat kegiatan kampus sejak direncanakan, pelaksanaan, penanganan dan pengendalian organisasi akademik. Gedung Rektorat memiliki peran tertinggi dalam sebuah kampus, karena didalamnya tempat pimpinan serta jajarannya, sehingga perlu pemeliharaan rutin demi kepentingan dan kenyaman bersama. Selama masa layan bangunan dapat mengalami perubahan kualitas atau penurunan kekuatan disebabkan berbagai faktor, baik, faktor alam, faktor manusia akibat penggunaan gedung, kebakaran atau sebab lainnya. Tujuan penelitian untuk mengetahui kesesuaian mekanisme pemeliharaan bangunan gedung Rektorat Universitas Teuku Umar berdasarkan Peraturan Menteri Pekerjaan Umum No. 24/PRT/M/2008. Metode pengumpulan data adalah dengan wawancara terhadap pengguna dan pengelola gedung serta penyebaran kuesioner terhadap pengguna dan pengelola gedung rektorat Universitas Teuku Umar. Pengolahan data kuesioner menggunakan metode skala likert, sedangkan yang data hasil wawancara dan observasi di lapangan diolah dianalisis menggunakan metode deskriptif. Hasil penilitian menunjukan bahwa tingkat kepuasan pengguna terhadap pemeliharan gedung rektorat dinilai sangat buruk dengan bobot nilai $19,05 \%$ berdasarkan skala likert. Mekanisme pemeliharaan menurut pengelola gedung, hasil perhitungan grafik persentase mencapai $73 \%$ menyatakan tidak sesuai. Berdasarkan hasil wawancara dengan pengelola gedung rektorat bahwa standar operasional dan konsep yang dijalankan tidak sesuai dengan Peraturan Menteri Pekerjaan Umum No. 24/PRT/M/2008. Kesimpulan dari hasil penlitian menunjukan bahwa mekanisme pemeliharaan gedung Rektorat Universitas Teuku Umar tidak sesuai dengan Peraturan Menteri Pekerjaan Umum No. 24/PRT/M/2008.
\end{abstract}

Kata Kunci: Pemeliharaan bangunan, gedung rektorat Universitas Teuku Umar

\begin{abstract}
Building maintenance is a requirement that must be done, especially buildings for public use. Teuku Umar University Rectorate Building is the center of campus activities since the planned, implementation, handling and control of academic organizations. The Rectorate Building has the highest role in a campus, because in it the place of leadership and staff, so it needs routine maintenance for the sake and mutual comfort. During the service life of the building may experience changes in quality or decrease in strength due to various factors, both natural factors, human factors due to building use, fire or other causes. The purpose of the study was to determine the suitability of the maintenance mechanism of the Teuku Umar University Rectorate building building based on Minister of Public Works Regulation No. 24 / PRT / M / 2008. The data collection method is by interviewing users and
\end{abstract}

Kajian Pemeliharaan Rutin Pada Gedung Rektorat Universitas Teuku Umar - Edi 
building managers as well as distributing questionnaires to users and managers of the Teuku Umar University Rectorate building. Questionnaire data processing uses the Likert scale method, while the data from interviews and observations in the field are processed using descriptive methods. The results of the study showed that the level of user satisfaction with the maintenance of the rector's building was considered very poor with a weight value of $19.05 \%$ based on the Likert scale. The maintenance mechanism according to the manager of rectorate building results of the calculation of the percentage of graphs reaching $73 \%$ states Not Suitable. Based on the results of interviews with the management of the rector's building that the operational standards and concepts that are implemented are not in accordance with Minister of Public Works Regulation No. 24 /PRT/M/2008. The conclusion from the research results shows that the maintenance mechanism of the Teuku Umar University Rectorate building is not in accordance with Minister of Public Works Regulation No.24/PRT/M/2008.

Keywords: Building maintenance, rectorate building Teuku Umar University.

\section{Latar Belakang}

Pemeliharaan bangunan secara konsisten sudah menjadi persyaratan yang harus dilakukan, terutama bagi bangunan yang difungsikan untuk kepentingan umum. Gedung rektorat Universitas Teuku Umar merupakan pusat administrasi perguruan tinggi, karena pada bangunan gedung tersebut semua kegiatan kampus direncanakan, diarahkan dan dikendalikan dalam sebuah organisasi akademik dan melayani kepentingan umum. Gedung Rektorat juga memiliki peran penting dalam sebuah kampus, karena di dalamnya terdapat ruang kerja pimpinan kampus berserta jajarannya, sehingga gedung rektorat sangat perlu pemeliharaan rutin demi kepentingan dan kenyaman.

Menurut Undang-Undang Republik Indonesia Nomor 28 Tahun 2002 tentang Bangunan Gedung. Pada umumnya bangunan direncanakan dapat beroperasi selama masa layan tertentu. Namun, selama masa layan tersebut bangunan dapat mengalami perubahan kualitas atau penurunan kekuatan yang disebabkan berbagai macam faktor. Faktor-faktor tersebut antara lain, faktor alam, faktor manusia, akibat penggunaan gedung, kebakaran atau sebab lainnya.

Berdasarkan gambaran masalah penelitian ini dapat dijabarkan bagaimana kondisi gedung Rektorat Universitas Teuku Umar ditinjau dari manajemen pemeliharaan gedung. Penelitian ini bertujuan untuk mengetahui kajian pemeliharaan gedung yang meliputi struktur, arsitektur dan utilitas. Pengambilan data dilaksanakan dengan melakukan observasi di lapangan dengan pemeriksaan kondisi fasilitas gedung dilakukan pada komponen struktur, arsitektur dan utilitas.

Pemeriksaan dilakukan dengan mengamati langsung kondisi fasilitas gedung. Data Pengamatan mengacu pada Peraturan Menteri Pekerjaan Umum No 24/PRT/M/2008 tentang Pedoman Pemeliharaan dan Perawatan Bangunan Gedung. Analisis data meliputi hasil pengamatan lapangan Metode pengolahan data, data diperoleh dari data primer hasil dari observasi dilakukan penyajian data secara deskriptif terhadap kondisi eksisting bangunan yang telah diidentifikasi. Setelah penelitian dilakukan, dapat memberikan informasi pada pengelola gedung bagaimana menajemen pemeliharaan yang baik. 


\section{Metode Penelitian}

\subsection{Lokasi Penelitian}

Dalam penelitian ini cara melakukan sesuatu dengan menggunakan sesuatu dengan fikiran seksama untuk mencapai tujuan (Cholid Nabuko \& Abu Ahmadi, 2007). lokasi yang akan menjadi tempat pengambilan sampel untuk data penelitian pada Gedung Rektorat Univeritas Teuku Umar Jalan Alue Peunyareng Meureubo Kabupaten Aceh Barat.

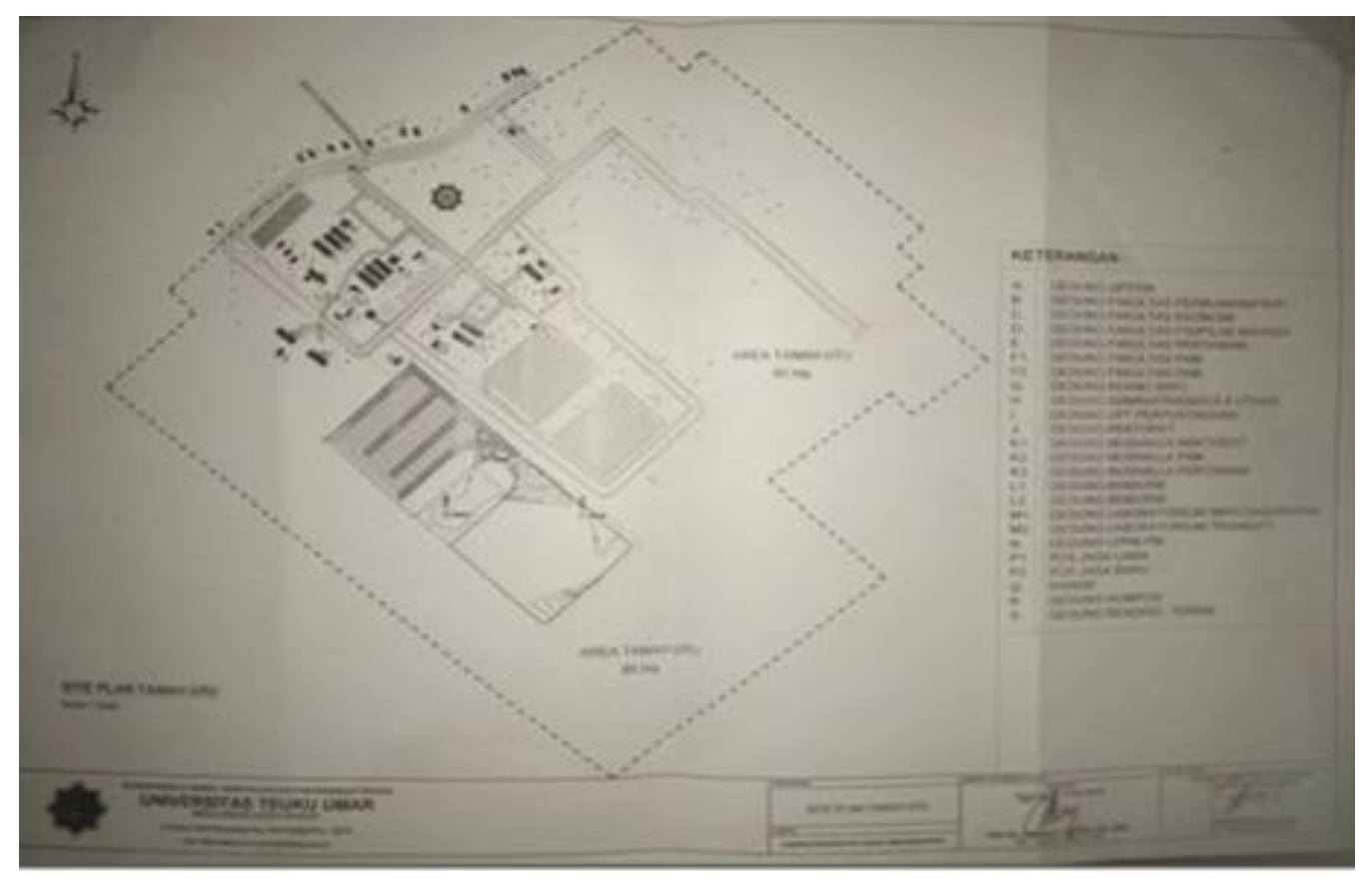

Gambar 1 Site Plan Universitas Teuku Umar

\subsection{Sumber dan Proses Pengumpulan Data}

Data yang diperlukan dalam penelitian ini meliputi data primer dan data sekunder, di mana data primer berupa data pengguna gedung Rektorat Universitas Teuku Umar.

a. Data primer adalah data yang didapat langsung dari responden (konsumen atau pengguna Gedung).

b. Data sekunder yang diperlukan dalam penelitian ini data perencanaan awal gedung untuk mengetahui spefikasi gedung, serta data struktur organisasi pengelolaan gedung tersebut. serta data lainnya yang diperlukan dalam penelitian.

Hasil dari observasi diperoleh tingkat kepuasan pengguna gedung, dari nilai tersebut dapat dilakukan pembobotan sehingga mendapatkan katagori yaitu tidak sesuai, kurang sesuai, cukup sesuai, sesuai dan sangat sesuai.

\subsection{Metode Analisis Data}

Data akan dianalisis sesuai prosedur dan metode analisis data pada penelitian ini adalah sebagai berikut: 
1. Penyebaran kuesioner mengikutin Peraturan Menteri Pekerjaan Umum No. 24/PRT/M/2008 tentang Pedoman Pemeliharaan dan Perawatan Bangunan Gedung. Survei lapangan dilakukan dengan meninjau langsung ke seluruh lokasi bangunan gedung Rektorat Universiatas Teuku Umar untuk mencari informasi faktual secara mendetail jenis-jenis fasilitas apa saja yang tersedia di gedung Rektorat Universitas Teuku Umar.

2. Observasi atau pengamatan secara langsung. Pada tahap ini target pengamatan dilakukan untuk mengetahui tingkat keselamatan, kesehatan, kenyamanan dan kemudahan pada gedung Rektorat Universitas Teuku Umar, sehingga dapat dievaluasi bagaimana kesesuain fasilitas yang ada pada bangunan gedung Rektorat Universitas Teuku Umar kemudian dianalisa kesesuaian berdasarkan standar pemeliharaan pada bangunan gedung.

Berikut ini adalah komponen bangunan gedung yang tersedia:

a. Arsitektur

Memelihara secara baik dan teratur unsur - unsur tampak luar bangunan sehingga tetap rapi dan bersih

b. Struktur

Memelihara secara baik dan teratur unsur-unsur struktur bangunan gedung dari pengaruh korosi, cuaca, kelembaban, dan pembebanan di luar batas kemampuan struktur, serta pencemaran lainnya.

c. Mekanikal

Memelihara dan melakukan pemerikaan berkala sistem distribusi air yang meliputi penyediaan air bersih, sistem instalasi air kotor, sistem hidran, sprinkler (alat penyemprot air), septik tank, serta unit pengolah limbah.

d. Elektrikal

Melakukan pemeriksaan periodik dan memelihara sistem instalasi listrik, baik untuk pasokan daya listrik maupun penerangan ruangan.

e. Tata ruang luar

Memelihara dengan baik dan teratur kondisi serta permukaan tanah dan atau halaman luar bangunan gedung.

f. Tata grha (House Keeping)

Pemeliharaan Kebersihan (Cleaning Service), program kerja pemeliharaan gedung meliputi program kerja harian, mingguan, bulanan, dan tahunan yang bertujuan memelihara kebersihan gedung yang meliputi kebersihan.

\section{Wawancara}

Tahapan selanjutnya adalah wawancara secara langsung yaitu untuk mendapatkan informasi dengan cara bertanya langsung kepada pengelola bangunan yang berkenan di wawancarai untuk mengetahui mekanisme pemeliharan serta kepuasan pengguna gedung Rektorat Universitas Teuku Umar. Jawaban-jawaban dari narasumber kemudian dicatat dan dijadikan sebagai dasar dalam melakukan pengolahan data. Fungsi lain dari wawancara adalah untuk mengetahui komponen apa saja yang selama ini dilakukan pemeliharanan di gedung Rektorat Universitas Teuku Umar. Dengan menganalisis hasil jawaban dari pihak yang berkompeten, dan juga untuk menjalin interaksi sosial dengan pengelola bangunan untuk mengetahui sejauh mana tingkat kepedulian pemilik dan pengelola bangunan khususnya. 
4. Pengolahan data kuesioner

Setelah dilakukan penyebaran kuesinoer kepada responden kemudian dilakukan pengolahan data, data diolah dan dibuat dalam bentuk tabulasi kemudian dilakukan uji kuantitatif dengan menggunakan skala likert. Data hasil kuesioner yang sudah disebarkan, kemudian dilaukan pembobotan dengan skala likert untuk mengkuantitatifkan parameter kinerja, sehingga data tersebut dikatagorikan menjadi beberapa tingkatan dalam skala.

Interpensi Skor Perhitungan sebagai berikut:

$$
\begin{aligned}
& X=\text { Skortertinggi li } \operatorname{ker} t x \text { Jumlah responden } \\
& Y=\text { Skorterendah li } \operatorname{ker} t x \text { Jumlah responden }
\end{aligned}
$$

Untuk menentukan interval digu8nakan rumus interval:

$$
I=100 / \text { Jumlah Skor li ker } t
$$

Untuk menentukan Index digunakan rumus index (\%) persen kriteria interpretasi:

$$
\%=\text { Total Skor } / Y \times 100
$$

\section{Hasil dan Pembahasan}

Gedung rektorat Universitas Teuku Umar merupakan pusat administrasi perguruan tinggi, karena pada bangunan gedung tersebut semua kegiatan kampus direncanakan, diarahkan dan dikendalikan dalam sebuah organisasi akademik dan melayani kepentingan umum. Gedung Rektorat juga memiliki peran penting dalam sebuah kampus, karena di dalamnya terdapat ruang kerja pimpinan kampus berserta jajarannya, sehingga gedung rektorat sangat perlu pemeliharaan rutin demi kepentingan dan kenyaman.

\subsection{Analisis Kuesioner}

Untuk mengetahui gambaran pemeliharaan gedung Rektorat Universitas Teuku Umar, digunakan analisis deskriptif berdasarkan tanggapan atas pertanyaan dalam kuesioner, item pertanyaan dalam pemeliharaan gedung digambarkan dalam bentuk Tabel Deskripsi Frekuensi Pengguna Langsung dan Pengguna Tak Langsung.

Tabel 1 Deskripsi pengguna langsung dan pengguna tidak langsung

\begin{tabular}{|c|l|c|c|}
\hline \multirow{2}{*}{ No } & \multicolumn{1}{|c|}{ Item Pertanyaan } & \multicolumn{2}{|c|}{ Jawaban } \\
\cline { 3 - 4 } & \multicolumn{1}{|c|}{ Sesuai } & $\begin{array}{c}\text { Tidak } \\
\text { sesuai }\end{array}$ \\
\hline 1 & $\begin{array}{l}\text { Pembersihan permukaan lantai dari kotoran dan debu } \\
\text { dilakukan setiap setiap hari }\end{array}$ & 14 & 1 \\
\hline 2 & $\begin{array}{l}\text { Pembersihan kaca dan jendela, termasuk pembatas (partisi) } \\
\text { ruangan dilakukan setiap 1 minggu }\end{array}$ & 3 & 12 \\
\hline 3 & Pembersihan plafon tripleks dilakukan setiap 3 bulan & 4 & 11 \\
\hline
\end{tabular}

Kajian Pemeliharaan Rutin Pada Gedung Rektorat Universitas Teuku Umar - Edi Mawardi, Samsunan, Fathurrahman 


\begin{tabular}{|c|c|c|c|}
\hline 4 & $\begin{array}{l}\text { Menurut bapak/ibu/saudara, bagaimana penanganan } \\
\text { kerusakan kecil pada plafond gypsum yang terkena bocoran } \\
\text { atap pipa diganti dengan lembar gypsum baru }\end{array}$ & 5 & 10 \\
\hline 5 & Pembersihan kusen dilakukan setiap 1 kali sehari & 0 & 15 \\
\hline 6 & Polituran kembali kusen kayu dilakukan setiap 6 bulan & 1 & 14 \\
\hline 7 & $\begin{array}{l}\text { Pemberian pelumas pada kunci, grendel, dan engsel } \\
\text { dilakukan minimal setiap } 2 \text { bulan sekali }\end{array}$ & 1 & 14 \\
\hline 8 & $\begin{array}{l}\text { Pemeliharaan pintu lipat/folding door (pembersihan dan } \\
\text { pelumasan) dilakukan setiap setiap hari }\end{array}$ & 6 & 9 \\
\hline 9 & Pembersihan tirai atau gordyn dilakukan setiap 2 bulan & 3 & 12 \\
\hline 10 & $\begin{array}{l}\text { Pemeliharaan terhadap AC (Air Conditioner) dilakukan } \\
\text { setiap } 2 \text { bulan }\end{array}$ & 4 & 11 \\
\hline 11 & $\begin{array}{l}\text { Dinding lapis kayu pada komponen arsitektur/interior } \\
\text { dibersihkan secara periodek setiap } 1 \text { bulan }\end{array}$ & 5 & 10 \\
\hline 12 & $\begin{array}{l}\text { Pemeliharaan terhadap dinding kaca dilakukan setiap } 1 \\
\text { tahun }\end{array}$ & 7 & 8 \\
\hline 13 & $\begin{array}{l}\text { Pembersihan terbuka air kotor pada sekitar bangunan } \\
\text { dilakukan setiap } 1 \text { bulan }\end{array}$ & 7 & 8 \\
\hline 14 & $\begin{array}{l}\text { Pembersihan dinding berdebu dan cermin } \\
\text { dilakukan setiap } 1 \text { kali sehari }\end{array}$ & 3 & 12 \\
\hline 15 & $\begin{array}{l}\text { Pembersihan menyedot, mengelap dan mengepel } \\
\text { dilakukan setiap hari }\end{array}$ & 6 & 9 \\
\hline 16 & $\begin{array}{l}\text { Pembersihan papan petunjuk lobby, lampu-lampu dan fiting } \\
\text { setiap } 1 \text { kali sehari }\end{array}$ & 0 & 15 \\
\hline 17 & $\begin{array}{l}\text { Pembersihan jalan dan tangga dilakukan setiap } 1 \text { kali } \\
\text { sehari }\end{array}$ & 7 & 8 \\
\hline 18 & $\begin{array}{l}\text { Pembersihan menyikat dan mengepel seluruh tangga } \\
\text { termasuk pijkan pegangan tangan dan nomor lantai } \\
\text { pada dinding dilakukan } 1 \text { kali sehari }\end{array}$ & 8 & 7 \\
\hline 19 & $\begin{array}{l}\text { Pembersihan sanitary fixtures (tempat cuci } \\
\text { tangan/wastafel, kloset duduk, kloset jongkok, urinal) } \\
\text { dilakukan setiap hari }\end{array}$ & 5 & 10 \\
\hline 20 & Pemeriksaan terhadap keran air dilakukan setiap? & 6 & 9 \\
\hline 21 & $\begin{array}{l}\text { Pemeriksaan terhadap saringan air (floor drain) pada lantai } \\
\text { kamar mandi/WC dilakukan setiap } 2 \text { bulan }\end{array}$ & 5 & 10 \\
\hline \multirow[t]{2}{*}{22} & $\begin{array}{l}\text { Pemeliharaan mencuci karpen dengan menggunakan dan } \\
\text { vacuum wet dan dry shampo setiap } 3 \text { bulan }\end{array}$ & 5 & 10 \\
\hline & Jumlah & 105 & 225 \\
\hline
\end{tabular}

Rekapitulasi hasil jawaban responden 15 orang dari pengguna langsung dan tidak langsung sebagai berikut:

Interpensi Skor berdasarkan persamaan (1), persamaan (2), persamaan (3) dan persamaan (\$) adalah sebagai berikut:

$X=$ Skortertinggi li ker $t x$ Jumlah responden

$225 \times 15=3,375$

\section{$Y=$ Skorterendah li ker $t x$ Jumlah responden \\ $105 \times 15=1,575$}

Rumus Interval:

$$
\begin{aligned}
& I=100 / \text { Jumlah Skor li ker } t \\
& \mathrm{I}=100 / 330=0,30
\end{aligned}
$$


Berdasarkan persamaan (4) Rumus index (\%) persen kriteria interpretasi:

$$
\begin{aligned}
& \%=\text { Total Skor } / Y \times 100 \\
& \%=0,30 / 1,575 \times 100=19,0476 \%
\end{aligned}
$$

Dari hasil jawaban kuesioner bahwa yang menjawab sesuai mendapat skor 105 dan yang menjawab tidak sesuai mendapat skor 225. Dari hasil pertihungan Interval mendapatkan nilai 19,0476\% katagori Sangat buruk.

Maka, pemeliharaan Gedung Rektorat Universitas Teuku Umar termasuk kategori Tidak Sesuai dengan Peraturan Menteri Pekerjaan Umum No. 24 Tahun 2008 Tentang Pedoman Pemeliharan Dan Perawatan Bangunan.

\begin{tabular}{|c|c|c|c|c|c|c|}
\hline \multirow[b]{2}{*}{ Pertanyaan } & \multicolumn{6}{|c|}{ Frekuensi Jawaban } \\
\hline & $\begin{array}{l}\text { Tidak } \\
\text { sesuai }\end{array}$ & $\begin{array}{c}\text { Kurang } \\
\text { sesuai }\end{array}$ & $\begin{array}{l}\text { Cukup } \\
\text { sesuai }\end{array}$ & Sesuai & $\begin{array}{c}\text { Sangat } \\
\text { sesuai }\end{array}$ & Total \\
\hline \multirow{2}{*}{$\begin{array}{l}\text { Bagaimana kebersihan } \\
\text { meja dan kursi menurut } \\
\text { bapak/ibu/saudara? }\end{array}$} & 3 & 4 & 2 & 6 & - & 15 \\
\hline & $20 \%$ & $27 \%$ & $13 \%$ & $40 \%$ & $0 \%$ & $100 \%$ \\
\hline \multirow{2}{*}{$\begin{array}{l}\text { Bagaimana kebersihan } \\
\text { lantai dan dinding } \\
\text { menurut } \\
\text { bapak/ibu/saudara? }\end{array}$} & 6 & 7 & 1 & 1 & 0 & 15 \\
\hline & $40 \%$ & $47 \%$ & $6 \%$ & $7 \%$ & $0 \%$ & $100 \%$ \\
\hline \multirow{2}{*}{$\begin{array}{l}\text { Bagaimana kondisi } \\
\text { ruang kerja menurut } \\
\text { bapak/ibu/saudara } \\
\text { menyangkut } \\
\text { kenyamanan? }\end{array}$} & 0 & 2 & 3 & 5 & 5 & 15 \\
\hline & $1 \%$ & $13 \%$ & $20 \%$ & $33 \%$ & $33 \%$ & $100 \%$ \\
\hline \multirow{2}{*}{$\begin{array}{l}\text { Bagaimana kondisi } \\
\text { tangga dan pegangan } \\
\text { tangga menurut } \\
\text { bapak/ibu/saudara? }\end{array}$} & 4 & 6 & 0 & 3 & 2 & 15 \\
\hline & $27 \%$ & $40 \%$ & $0 \%$ & $20 \%$ & $13 \%$ & $100 \%$ \\
\hline \multirow{2}{*}{$\begin{array}{l}\text { Bagaimana } \\
\text { perlengkapan dalam } \\
\text { toilet menurut } \\
\text { bapak/ibu/saudara? }\end{array}$} & 2 & 5 & 4 & 4 & - & 15 \\
\hline & $13 \%$ & $33 \%$ & $27 \%$ & $27 \%$ & $0 \%$ & $100 \%$ \\
\hline \multirow{2}{*}{$\begin{array}{l}\text { Bagaimana kualitas } \\
\text { pintu kaca menurut } \\
\text { bapak/ibu/saudara? }\end{array}$} & 3 & 3 & 6 & 3 & 0 & 15 \\
\hline & $20 \%$ & $20 \%$ & $40 \%$ & $20 \%$ & $0 \%$ & $100 \%$ \\
\hline \multirow{2}{*}{$\begin{array}{l}\text { Bagaimana kebersihan } \\
\text { kaca dan jendela } \\
\text { menurut } \\
\text { bapak/ibu/saudara? }\end{array}$} & 1 & 0 & 1 & 9 & 4 & 15 \\
\hline & $7 \%$ & $0 \%$ & $7 \%$ & $60 \%$ & $27 \%$ & $100 \%$ \\
\hline \multirow{2}{*}{$\begin{array}{l}\text { Bagaimana kebersihan } \\
\text { saluran air kotor pada } \\
\text { sekitarbangunan } \\
\text { menurut } \\
\text { bapak/ibu/saudara? }\end{array}$} & 9 & 3 & 1 & 1 & 1 & 15 \\
\hline & $60 \%$ & $20 \%$ & $7 \%$ & $7 \%$ & $7 \%$ & $100 \%$ \\
\hline \multirow{2}{*}{$\begin{array}{l}\text { Bagaimana kondisi cat } \\
\text { di bagian luar } \\
\text { bangunanmenurut } \\
\text { bapak/ibu/saudara? }\end{array}$} & 10 & 5 & 0 & 0 & - & 15 \\
\hline & $67 \%$ & $33 \%$ & $0 \%$ & $0 \%$ & $0 \%$ & $100 \%$ \\
\hline
\end{tabular}

Tabel 2 Persepsi responden pengelola gedung rektorat universitas teuku umar

Kajian Pemeliharaan Rutin Pada Gedung Rektorat Universitas Teuku Umar - Edi Mawardi, Samsunan, Fathurrahman 


\begin{tabular}{|l|c|c|c|c|c|c|}
\hline $\begin{array}{l}\text { Bagaimana kebersihan } \\
\text { kamar mandi menurut } \\
\text { bapak/ibu/saudara? }\end{array}$ & 10 & 2 & 2 & 1 & 0 & 15 \\
\cline { 2 - 7 } & $67 \%$ & $13 \%$ & $13 \%$ & $7 \%$ & $0 \%$ & $100 \%$ \\
\hline $\begin{array}{l}\text { Bagaimana kondisi } \\
\text { kran air menurut } \\
\text { bapak/ibu/saudara? }\end{array}$ & 71 & 2 & 1 & 1 & - & 15 \\
\hline $\begin{array}{l}\text { Bagaimana kebersihan } \\
\text { wastafel, kloset duduk, } \\
\text { kloset jongkok, urinal } \\
\text { menurutbapak/ibu/saud } \\
\text { ara? }\end{array}$ & 7 & 3 & 2 & 3 & - & 15 \\
\hline $\begin{array}{l}\text { Bagaimana kebersihan } \\
\text { dinding kamar mandi } \\
\text { menurut } \\
\text { bapak/ibu/saudara? }\end{array}$ & 10 & 3 & $13 \%$ & $7 \%$ & $0 \%$ & $100 \%$ \\
\cline { 2 - 7 } & $67 \%$ & $20 \%$ & $6 \%$ & $7 \%$ & $0 \%$ & $100 \%$ \\
\hline
\end{tabular}

Pada Tabel 2 dapat dilihat bahwa penilaian responden sebagian besar mengatakan tidak sesuai dengan pemeliharaan gedung Rektorat Universitas Teuku Umar. Namun nilai sesuai diposisi kedua sedangkan untuk nilai kurang setuju di posisi ketiga, cukup sesuai diposisi keempat dan sangat sesuai diposisi kelima, dimana dari total 15 responden. Dari 15 responden mempuyai 15 penilaian dari 1 variabel yaitu penilaian terhadap program pemeliharaan. Pengelola gedung adalah pengelola yang terkait dengan bagian pemeliharaan berserta anggota atau pekerja yang bertindak langsung dalam proses pemeliharan gedung Rektorat Universitas Teuku Umar. Untuk melihat hasil persentase dari tanggapan responden pemeliharaan Gedung Rektorat Universitas Teuku Umar dapat dilihat pada Gambar 2.

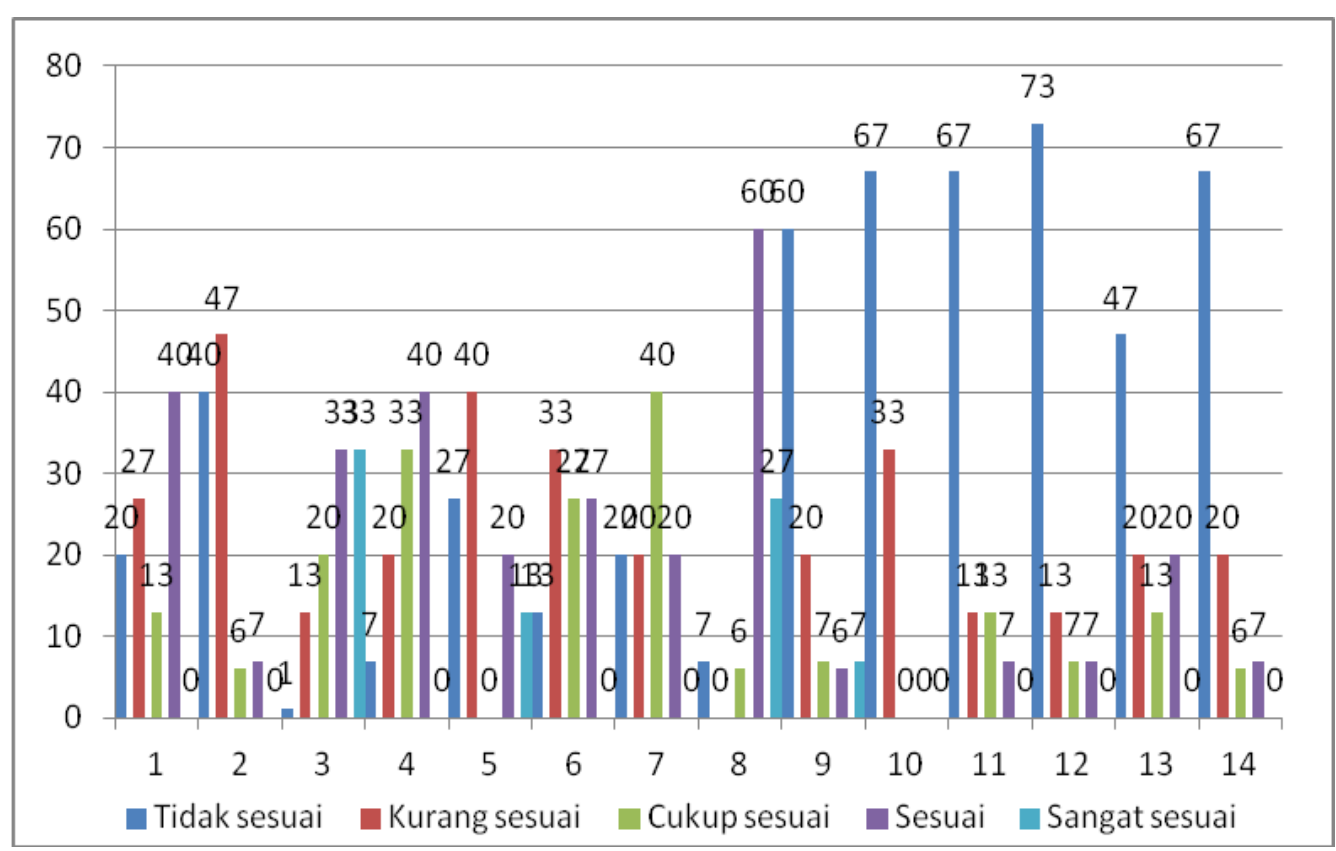

Gambar 2 Grafik persentase responden pengelola gedung 
Berdasarkan jawaban kuesioner pengelola gedung Rektorat Universitas Teuku Umar mendapatkan nilai tertinggi 73\% Tidak sesuai, maka dapat dikatakan bahwasannya pengelola gedung Rektorat Universitas Teuku Umar belum semuanya sesuai atau tidak sesuai dengan Peraturan Menteri Pekerjaan Umum No. 24 Tahun 2008 Tentang Pedoman Pemeliharan Dan Perawatan Bangunan.

\section{Kesimpulan dan Saran}

\subsection{Kesimpulan}

Berdasarkan hasil penilitian yang dilakukan, maka dapat di ambil kesimpulan sebagai berikut:

1. Hasil penelitian menunjukan bahwa perhitungan Interval pengguna gedung diperoleh nilai $19,0476 \%$. Hal ini menunjukan bahwa mekanisme pemeliharaan bangunan gedung Rektorat Universitas Teuku Umar belum sesuai dengan Peraturan Menteri Pekerjaan Umum No.24/PRT/M/2008. Mekanisme pengelolaan perawatan bangunan gedung Rektorat Universitas Teuku Umar, dimana hasil $73 \%$ tidak mengikuti Peraturan Menteri Pekerjaan Umum No.24/PRT/M/2008.

2. Hasil wawancara dengan pengelola gedung menunjukan bahwa ada dilakukan standar operasionl pemeliharaan gedung tetapi sifat nya tidak terstruktur karena keterbatasan biaya.

3. Pemeliharaan gedung Rektorat Universitas Teuku Umar tidak mengacu pada Peraturan Menteri Pekerjaan Umum No.24/PRT/M/2008, karena untuk proses pemeliharaan menunggu laporan apa yang harus di perbaiki dan diketahui setelah terjadi bukan karena pengecekan secara berkala.

\subsection{Saran}

Adapun saran-saran yang dapat diberikan dalam penilitian ini sebagai bentuk rekomendasi sebagai berikut:

1. Sebaiknya Mekanisme pemeliharaan bangunan gedung Rektorat Universitas Teuku Umar mengikuti Peraturan Menteri Pekerjaan Umum No.24/PRT/M/2008. Sehingga proses pemeliharaan berjalan dengan baik dan rutin, agar bangunan tersebut tetap berdiri kokoh dan terawat.

2. Sebaiknya pihak pengelola gedung melakukan pengecekan rutin terhadap komponen-komponen gedung sehingga dapat di atasi dengan cepat jika ada kerusakan yang harus diperbaiki

3. Untuk mendapatkan hasil pemeliharaan yang baik adanya kesadaraan dari pengguna gedung maupun pengelola dengan menjaga fasilitas yang ada sehingga menciptakan gedung yang terawat dan bersih.

\section{Daftar Kepustakaan}

Cholid Nurbuko dan H, Abu Achmadi., 2007. Metode Penelitian. Jakarta: Bumi Aksara 
Edi Mawardi., 2018, Kajian Konsep Operasional pemeliharaan gedung SMA Bina Generasi Bangsa Meulaboh Aceh Barat.Jurnal Teknik Sipil Volume 1, Special issue nomor 4 Hal 811-822 Universitas Syiah Kuala.

Ismiyati, (2004), Statitistika dan Aplikasinya, Magister Teknik Sipil Universitas Diponegoro, Semarang.

Kementrian Pekerjaan Umum, 2008, Peraturan Menteri Pekerjaan Umum Nomor 24/PRT/M/2008 tentang Pedoman Pemeliharaan dan Perawatan Bangunan Gedung, Jakarta.

Mulyandari,Hestin dan Rully Saputra., 2011. Pemeliharaan Bangunan (Basic Skill Facility Management), Yogyakarta: Andi.

Pemerintah Indonesia, 2002, Undang-Undang No. 282002 tentang Bangunan Gedung. Sekretariat Negara. Jakarta.

Sugiono. 2010, Metode Penelitian Kuantitatif, kualitatif dan r \& d. Bandung: Alfabeta.

Usman, K., dan Winandi, R, 2009.Kajian Manajemen Pemeliharaan Gedung (Building Maintenance) di Universitas Lampung, Lampung: Jurnal Sipil dan Perencanaan Volume 13 Universitas Lampung.

Win Ridho Miko., 2017. Analisis Pemeliharaan Bangunan Gedung Biro Pusat Administrsi Universitas Sumatera Utara: Universitas Sumatera Utara. 